\title{
Videokeratography database of normal human corneas
}

\author{
Yaron S Rabinowitz, Huiying Yang, Yuri Brickman, Judy Akkina, Carleen Riley, Jerome I \\ Rotter, Janet Elashoff
}

Cornea Genetic Eye Medical Clinic Cedars-Sinai Medical Center, Los Angeles,

USA

Y S Rabinowitz

Y Brickman

J Akkina

C Riley

Division of

Biostatistics,

Department of

Medicine,

Cedars-Sinai Medical

Center, Los Angeles,

USA

J Elashoff

Department of

Pediatrics, UCLA

School of Medicine,

Los Angeles, USA

Y S Rabinowitz

HYang

J I Rotter

Department of

Medicine, UCLA

School of Medicine,

Los Angeles, USA

J I Rotter

Department of Ophthalmology, Jules Stein Eye Institute, UCLA School of

Medicine, Los Angeles, USA

Y S Rabinowitz

Department of Biomathematics, UCLA School of Medicine, Los Angeles, USA

J Elashoff

Correspondence to: Yaron S Rabinowitz, MD, Cornea-Genetic Eye Medical Clinic, Suite 1102, Mark Goodson Building,

Cedars-Sinai Medical

Center, 444 South San

Vicente Blvd, Los Angeles,

CA 90048, USA.

Accepted for publication 11 March 1996

\begin{abstract}
Aim-To form a database of videokeratography patterns and quantitative indices describing normal human corneas using the absolute scale.

Methods-Both eyes of 195 normal subjects were examined with a TMS-1 videokeratoscope. Videokeratographs were divided into 10 categories based on a classification scheme devised from the absolute scale and analysed with 10 quantitative indices devised to describe phenotypic features of keratoconus videokeratographs. Correlations were sought between videokeratograph patterns and quantitative indices. Additionally, data were analysed for differences in age, sex, and ethnicity.
\end{abstract}

Results-For symmetric videokeratography patterns, analysis in the absolute scale was similar to a previous study done in the normalised scale. In the asymmetric categories, analyses differed markedly. Using the absolute scale and our classification scheme more variation in normal videokeratography patterns could be appreciated. There was good correlation between quantitative indices and videokeratography patterns. Neither videokeratography patterns nor indices differed significantly between sex, ethnic groups, or age using two way analysis of variance.

Conclusions-Pattern analysis of videokeratographs in the absolute scale using, a standard classification scheme, may be more useful in trying to determine whether a cornea is normal or represents subtle early disease than analysis in the normalised scale. Quantitative indices could remove the subjectivity from the decision making process thus facilitating universal reproducibility of videokeratography data interpretation.

(Br F Ophthalmol 1996;80:610-616)

Computer assisted videokeratography is a sensitive method for evaluating the anterior corneal surface and allows for detailed qualitative and quantitative analysis of corneal shape derived from the corneal power maps generated by current generation videophotokeratoscopes. ${ }^{1-7}$ In order to determine the earliest changes on the anterior corneal surface found in disease states, we first need to analyse the spectrum of topography that exists in normal human corneas as measured with videokeratography.
Two previous studies have used videokeratography to study normal human corneas; one used the LSU topography system, ${ }^{8}$ and the other the corneal modelling system, analysing videokeratographs in the normalised scale. ${ }^{9}$ Neither of these two studies performed a detailed analysis of the correlation between qualitative and quantitative data, derived from videokeratographs, nor analysed their data with respect to age, sex, or ethnicity.

We used the topographic modelling system (TMS-1) to study patients from diverse ethnic backgrounds in order to form a database consisting of qualitative and quantitative descriptors of normal human corneas with videokeratography, using a single colour scale referred to as the absolute scale. ${ }^{10}$ Furthermore, our data have been analysed for correlation between indices and patterns; differences between eyes, and differences between age, sex, and ethnicity. These data provide the most extensive analysis of videokeratographs of normal human corneas reported to date.

\section{Subjects and methods}

SELECTION OF SUBJECTS

We prospectively analysed 390 corneas of 195 normal subjects.

The subjects studied were normal volunteers who were employees of the Cedars-Sinai Medical Center (CSMC), Los Angeles, California. Exclusion criteria for entry into the study included contact lens wear; corneal disease; previous ocular surgery; prior ocular trauma; retroillumination signs for keratoconus; refractive error of greater than 5.00 dioptres (D) of myopia, 5.00 D of hyperopia, or $5.00 \mathrm{D}$ of astigmatism as determined by measuring spectacle correction with a lensometer; dry eye syndrome; family history of keratoconus; and a history of any disease previously reported in association with keratoconus.

The mean age of the study sample was 39 (SD 12) years. Eighty males and 115 females were studied (Table 1).

Table 1 Study subjects

\begin{tabular}{lccllc}
\hline Ethnic group & White & Hispanic & Black & Asian & Total \\
\hline $\begin{array}{l}\text { Number } \\
\text { Age }\end{array}$ & 116 & 27 & 31 & 21 & 195 \\
$\quad$ Mean & 41 & 32 & 37 & 38 & 39 \\
$\quad$ SD & 12 & 8 & 12 & 10 & 12 \\
Sex & & & & & \\
$\quad$ Male & 46 & 12 & 10 & 12 & 80 \\
$\quad$ Female & 70 & 15 & 21 & 9 & 115 \\
M/F ratio & 0.66 & 0.80 & 0.48 & 1.33 & 0.70 \\
\hline
\end{tabular}


METHODS OF CLINICAL EXAMINATION

Before being entered into the study, all subjects were asked to review a patient information sheet approved by the institutional review board for protection of human subjects. Subjects were then asked to complete a questionnaire regarding their family, medical, and surgical history. The following clinical examinations were performed on each patient: Snellen visual acuity, spectacle correction (read with a lensometer), slit-lamp biomicroscope examination, and examination with a direct ophthalmoscope and a retinoscope to rule out such retroillumination signs of keratoconus, as the oil droplet sign and the scissor reflex. Videokeratography was performed on both eyes of each study subject with the TMS-1 (Computed Anatomy, Inc, New York, NY, USA), software version 1.61. The following measures were taken to ensure quality control and reproducibility of video images. At least four pictures of each subject were taken; 22 of the 25 rings had to be fully digitised; lids had to be kept wide open and off the cornea without assistance or eyelid compression; all pictures had to be within $0.25 \mathrm{D}$ of each other as measured by simulated keratometry $(\operatorname{sim} \mathrm{K})$ readings; to ensure proper fixation and alignment the cross hair had to be in the centre of the pupil for each examination. The tenets of the Declaration of Helsinki were followed in

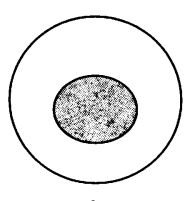

A

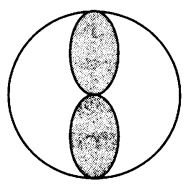

F

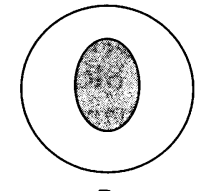

B

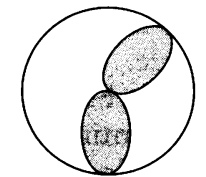

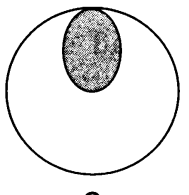

C

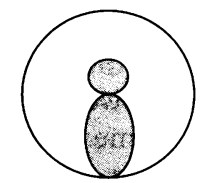

$\mathrm{H}$

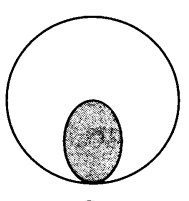

D

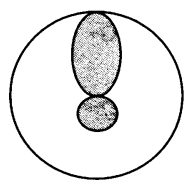

I

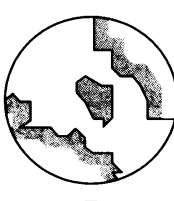

E

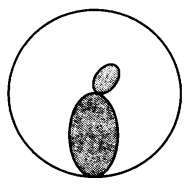

$J$
Figure 1 Videokeratography pattern classification scheme based on the absolute scale: $A$, round; $B$, oval; $C$, superior steepening; $D$, inferior steepening; $E$, irregular; $F$, symmetric bowtie; $G$, symmetric bowtie with skewed radial axes; $H$, asymmetric bowtie with inferior steepening (AB/IS); I, asymmetric bowtie with superior steepening; $\mathcal{F}$, asymmetric bowtie with skewed radial axes $(A B / S R A X)$.
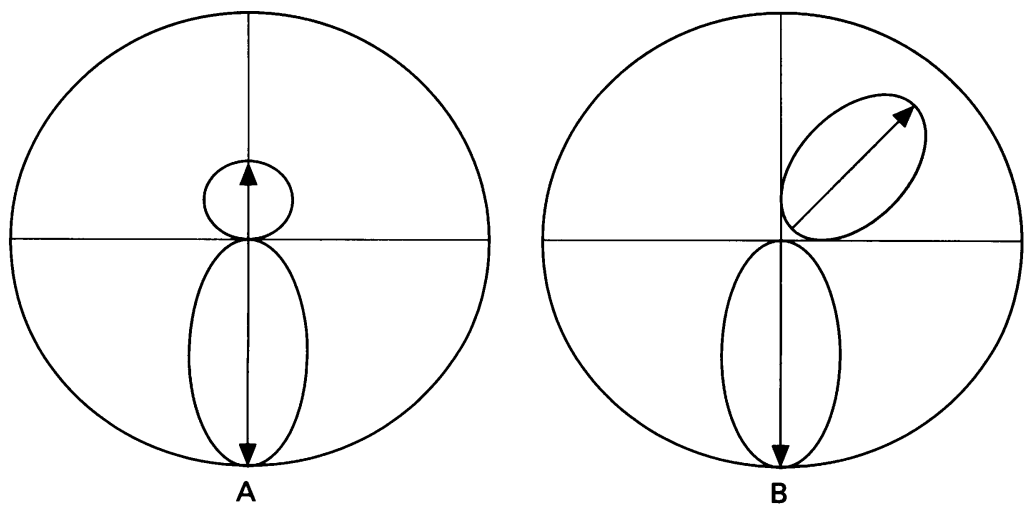

Figure 2 Schematic illustration of how to determine whether a pattern is $A B / I S$ or $A B / S R A X$. A line is drawn to bisect the upper and lower lobes of the asymmetric bowtie (see solid lines), if there is no significant deviation from the vertical meridian (that is, no skewing), the pattern is designated as AB/IS (as in A); if the lines bisecting the two lobes appear skewed by more than 30 degrees from the vertical meridian (that is, 150 degrees from one another), it is labelled as $A B / S R A X$ (as in B). taking videokeratographs. The best videokeratograph of four was selected on the basis of the quality of the keratoscope mires by visual inspection. All videokeratographs were printed in the absolute scale, in which the colours represent $1.5 \mathrm{D}$ intervals between $35 \mathrm{D}$ and 50.5 $\mathrm{D}$ and $5 \mathrm{D}$ intervals outside this range.

\section{QUALTTATIVE TOPOGRAPHY CLASSIFICATION} SYSTEM

Each videokeratograph from each eye was put into one of 10 categories as judged subjectively by three observers, who agreed on the same pattern in $90 \%$ of videokeratographs studied. The other $10 \%$ of videokeratographs were assigned according to a pattern agreed to by at least two of the three observers. In no instance was there disagreement about pattern classification among all three observers.

The categories were as follows: round, oval, irregular, inferior steepening (IS), superior steepening (SS), symmetric bowtie (SB), and asymmetric bowtie (AB) with $\mathrm{SS}, \mathrm{AB}$ with IS, $S B$ with skewed radial axes (SRAX), and $A B$ with SRAX (Figs 1 and 2). The steeper of two predominant colours in the central two thirds of the cornea was used to determine the pattern type. To be included in the classification scheme a colour had to occupy at least $10 \%$ or more of the central two thirds of the corneal map. In the IS and SS categories the steepest colour had to occupy at least $10 \%$ of the inferior or superior part of the central two thirds of the cornea. Any colours found completely outside the central two thirds of the cornea were excluded from this classification scheme. The colours used for this classification system were blue, green, yellow, orange, and orange-red. Criteria for subclassifying videokeratographs as round, oval, $\mathrm{SB}, \mathrm{AB}$, or irregular were those described by Bogan and colleagues. ${ }^{9} \mathrm{AB}$ was divided into three subcategories: SS (if the superior lobe had a greater surface area than the inferior lobe), IS (if the inferior lobe occupied a greater surface area than the superior lobe), and SRAX (if the angle between the steepest radial axes above and below the horizontal meridian appeared less than 150 degrees on visual inspection) (Fig 2). Three additional categories were as follows: IS (if there was an area of increased surface power below the horizontal meridian but none above), SS (if there was an area of increased surface power above the horizontal meridian but none below), and SB with SRAX (if the angular difference between steepest radial axes above and below the horizontal meridian appeared to be less than 150 degrees in SB patterns).

\section{QUANTITATIVE INDICES}

The following quantitative indices were recorded.

(1) Indices previously described in detail ${ }^{5}$ :

(a) simulated keratometry readings $(\operatorname{sim} \mathrm{K})$,

(b) minimum keratometry readings ( $\min \mathrm{K}$ ),

(c) surface regularity index (SRI), and

(d) surface asymmetry index (SAI).

(2) Indices analysed for each eye by a newly devised computer software program: 
(a) Central $\mathrm{K}$, calculated by averaging the dioptric power points on rings 2,3 , and 4 of the videokeratographs generated by the TMS-1. A total of 768 data points are averaged to give a single dioptric reading descriptive of the central corneal power.

(b) I - S value, calculated by averaging data points on rings 14,15 , and 16 of the videokeratographs generated by the TMS- 1 instrument approximately $3 \mathrm{~mm}$ inferior to the centre of the cornea at 30 degree intervals (that is, 210, 240, 270, 300, and 330 degrees) (five data points on each of the three rings). The values of these 15 data points are averaged to give a single dioptric value, I. A similar calculation is made by averaging the data points on rings 14,15 , and 16 at $3 \mathrm{~mm}$ superior to the centre of the cornea at 30 degree intervals (that is, 30,60 , 90,120 , and 150 degrees). These 15 points are averaged to give a single dioptric value, $S$. The superior value is subtracted from the inferior value to give the $I-S$ value. A positive $I-S$ value indicates a relatively steeper inferior cornea, while negative $I-S$ values indicates a relatively steeper superior cornea. (3) The $R$ versus $L$ index, calculated by subtracting the central $K$ of the left eye from the central $\mathrm{K}$ of the right eye. (The values central $K, I-S$ value, and $R$ versus $L$ index described here, are a more detailed method of analysis of similar indices that have previously been described. ${ }^{11} 12$

(4) New indices that were analysed by a computer software program and attempts to quantify other features seen in keratoconus videokeratographs:

(a) CA, the steepest point on the cornea and its location (measured in dioptres, location in millimetres (distance), and degrees (angle) relative to the centre of the videokeratograph)

(b) C - P, the difference between the steepest central point and the flattest peripheral point on each cornea (in dioptres), and

(c) $\mathrm{AD}$, the angular difference between the maximum slope above the horizontal meridian and the maximum slope below the horizontal meridian, calculated from rings 4 to 15 by a computer software program, a measure of relative skewing of these radial axes (in degrees) (Fig 2). (To ensure accuracy and reproducibility of all quantitative measures

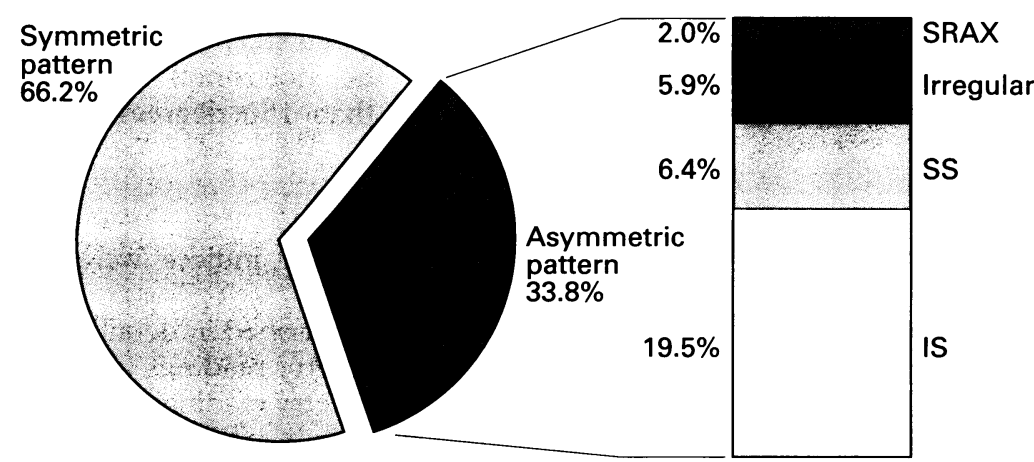

Figure 3 Schematic presentation of approximate videokeratography pattern distribution in the normal population. $S R A X=$ skewed radial axes; $S S=$ superior steepening; $I S=$ inferior steepening. above, indices from at least two different videokeratographs of the same eye had to be within $0.2 \mathrm{D}$ of each other.)

STATISTICAL ANALYSIS

All data including demographic information, clinical examination, and both qualitative and quantitative data from each videokeratograph were entered into a database created with the DATA EASE software program. All statistical analyses were performed with BMDP, a statistical software package. ${ }^{13}$ Normality was tested for all continuous variables by Shapiro and Wilk's statistic. ${ }^{14}$ Analysis of variance was used to test for mean difference in quantitative indices between different qualitative videokeratography patterns. Two way analysis of variance was used to test for mean differences in quantitative indices between racial and sex groups. Correlations of indices between two eyes were evaluated using the Pearson correlation coefficient. ${ }^{15}$ (For SAI, a logarithmic transformation was made to obtain a more ready normal distribution before correlations were computed.)

\section{Results}

DISTRIBUTION OF VIDEOKERATOGRAPHY

PATTERNS

The percentage of the total sample group comprising each pattern is shown in Table 2 , and the distribution of patterns is illustrated in Figure 3. The majority of normal subjects $(66 \%)$ had symmetric patterns (round, oval, or symmetric bowtie). SRAX patterns were rare, comprising less than $2 \%$ of the study sample.

\section{DESCRIPTION OF QUANTITATIVE INDICES}

Table 3 summarises all indices studied. The mean central $\mathrm{K}$ value and average $\operatorname{sim} \mathrm{K}$ had the same dioptric value. There was very little central power difference between two corneas of the same eye as quantified by $R$ versus $L$ indices, or within an individual cornea as quantified by the $\mathrm{I}-\mathrm{S}$ value. Corneas flattened on average $4.3 \mathrm{D}$ from the centre to the periphery. The median angular difference between the steepest radial axis above and below the horizontal meridian was within 25 degrees of 180 degrees for all corneas and within 5 degrees of 180 degrees for corneas with more than $1.5 \mathrm{D}$ of astigmatism.

Table 2 Videokeratograph distribution in 195 normal individuals

\begin{tabular}{lccc}
\hline VK pattern & $\begin{array}{l}\text { Right eye } \\
(n)\end{array}$ & $\begin{array}{l}\text { Left eye } \\
(n)\end{array}$ & Total (\%) \\
\hline Oval & 44 & 37 & 20.8 \\
Round & 46 & 52 & 25.1 \\
Superior steep & 9 & 7 & 4.1 \\
Inferior steep & 22 & 25 & 12.1 \\
Symmetric bowtie & 37 & 42 & 20.3 \\
Asymmetric & & & \\
$\quad$ bowtie-superior steep & 6 & 3 & 2.3 \\
Asymmetric bowtie-inferior & 14 & 15 & 7.4 \\
$\quad$ steep & 14 & 9 & 5.9 \\
Irregular & 0 & 2 & 0.5 \\
Asymmetric bowtie-SRAX & 3 & 3 & 1.5 \\
Symmetric bowtie-SRAX & 35 & 195 & 100.0 \\
Total & 195 & \\
\hline
\end{tabular}

$\mathrm{VK}=$ videokeratography; SRAX=skewed radial axes 
Table 3 Videokeratography indices (mean (SD))

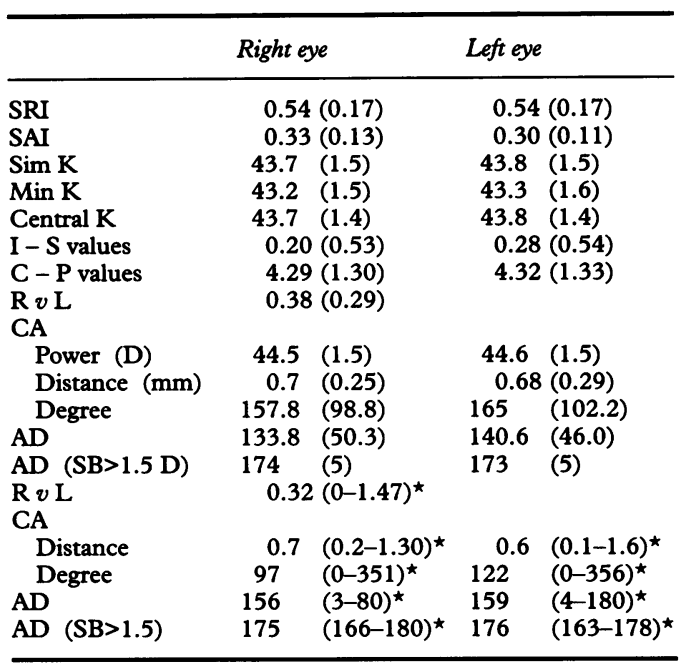

$\mathrm{SRI}=$ surface regularity index; $\mathrm{SAI}=$ surface asymmetry index Sim $\mathrm{K}=$ simulated keratography; $M$ in $\mathrm{K}=$ minimum keratography; Central $\mathrm{K}=$ central cornea power; $\mathrm{I}-\mathrm{S}=$ inferior minus superior; $C-P=$ difference between central and peripheral power; $R v L=$ right versus left; $C A=$ corneal apex location; $\mathrm{AD}=$ angular difference between steepest radial axes above and below horizontal meridian; SB $>1.5 \mathrm{D}=$ symmetric bowtie with more than $1.5 \mathrm{D}$ of astigmatism.

^Median (range).

Table 4 Comparison of symmetric and non-symmetric patterns (SD)

\begin{tabular}{llll}
\hline & $\begin{array}{l}\text { Oval/round, } \\
\text { Sym bowtie }\end{array}$ & Others & pValue \\
\hline n & 130 & 65 & \\
I - S mean & $0.12(0.43)$ & $0.36(0.67)$ & 0.002 \\
SAI mean & $0.32(0.14)$ & $0.34(0.11)$ & 0.227 \\
SRI mean & $0.53(0.18)$ & $0.55(0.17)$ & 0.535 \\
\hline
\end{tabular}

Sym=symmetric; I - S=inferior minus superior dioptric asymmetry; $\mathrm{SAI}=$ surface asymmetry index; $\mathrm{SRI}=$ surface regularity index.

(Only right eyes were used in this comparison.)

Table 5 Videokeratography patterns: comparison with Bogan et al's study ${ }^{9}$

\begin{tabular}{lcc}
\hline & Bogan et al & This study \\
\hline Round & $22.6 \%$ & $20.8 \%$ \\
Oval & $20.8 \%$ & $25.1 \%$ \\
Irreg & $7.1 \%$ & $5.9 \%$ \\
S/bowtie & $17.5 \%$ & $21.5 \%$ \\
Albowtie & $32.1 \%$ & $7.4 \%$ \\
Sym group & $60.9 \%$ & $67.4 \%$ \\
\hline
\end{tabular}

Irreg=irregular; $S=$ symmetric; $A=$ asymmetric; $S y m$ group=symmetric group.

AGE, RACE, AND SEX COMPARISONS

Except for the $\mathrm{C}-\mathrm{P}$ index, which had significantly greater values for black males than for Asian males with respect to both eyes (5.7 versus $3.7 \mathrm{D} ; \mathrm{p}<0.01$ ), none of the quantitative indices and videokeratography patterns showed statistically significant differences with regard to race or sex. Age did not correlate with any of the variables measured.

\section{RELATION BETWEEN VIDEOKERATOGRAPHY}

PATTERNS AND QUANTITATIVE INDICES

The $\mathrm{I}-\mathrm{S}$ value is distributed around zero, the maximum value being less than 1.8 on both sides. The absolute $I-S$ value is significantly less for corneas with symmetric patterns (oval, round, and SB) than for those with asymmetric patterns $(p=0.01)$ (Table 4$)$. There are no statistically significant differences between sym- metric and asymmetric patterns for SRI and SAI values. The symmetric bowtie (SB) patterns had significantly more keratometric astigmatism than the oval/round $(\mathrm{O} / \mathrm{R})$ patterns and the other asymmetric patterns (AP). The AP had more astigmatism than the $O / R$ patterns (SB, $1.36 \mathrm{D} ; \mathrm{AP}, 0.79 \mathrm{D} ; \mathrm{O} / \mathrm{R}, 0.60 \mathrm{D}$; $(\mathrm{p}=<0.01)$.

COLOUR AND PATTERN CORRELATION

The majority of the maps in this study were yellow on green; orange in $22.5 \%$, orange-red $(47.5-49 \mathrm{D})$ in $3.6 \%$ of the maps, and red (49-50.5 D) in one map (0.25\%).

\section{Correlation between two eyes}

Based on pattern recognition alone, enantiomorphism was observed in $43 \%$ of videokeratographs. All measurements of central corneal power (central $\mathrm{K}, \operatorname{sim} \mathrm{K}, \min \mathrm{K}$, and CA) showed a highly significant correlation between the two eyes $(r>0.9)$, while measurements of difference in power points $(\mathrm{I}-\mathrm{S}$ and $\mathrm{C}-\mathrm{P}$ values) showed moderate correlation $(r=0.5-0.9)$.

\section{Discussion}

Our study provides new and detailed information about videokeratography patterns and quantitative indices in normal human corneas and confirms previous observations regarding normal corneal shape. Compiling a database of patterns and indices, as we have done in this study, enhances the clinician's diagnostic capabilities in several areas: (1) differences in patterns that appear similar when analysed in the normalised scale can be discerned by pattern analysis; (2) analysis of quantitative indices allows for detection of subtle differences in videokeratographs which appear similar even when analysed in the absolute scale; and (3) quantitative indices allow one to determine whether an unusual videokeratography pattern depicts a subtle topographic abnormality in a clinically normal cornea such as seen in 'early' keratoconus or merely depicts a variation in normal corneal topography.

Two previous studies have described the variation in videokeratography patterns that exists in normal human corneas. ${ }^{8}$ In one, Bogan and colleagues ${ }^{9}$ used the normalised scale to develop a qualitative classification system for normal videokeratographs using five basic subgroups (Table 5). We expanded this classification scheme to 10 subgroups to allow for a more detailed pattern analysis and in addition used the absolute scale. We used the absolute scale for two reasons: (1) because a study by Wilson $e t$ al suggested that a scale with 1.5 D intervals is adequate for recognising pathology, ${ }^{16}(2)$ the use of a single consistent scale with a standard set of reference colours makes it easier for different observers to determine whether anterior corneal power changes have occurred over time based on pattern and colour recognition alone. ${ }^{15}$

Despite the use of different colour scales, our analysis of videokeratography patterns was similar in all the major subgroups except for the $\mathrm{AB}$ group. As regards this latter group 
Bogan et al suggested that it might be attributed by technical problems or contact lens wear. ${ }^{9}$ However, since we controlled carefully for those factors, we believe this group forms part of the spectrum of normal corneal topography. The AB group, larger in Bogan et $a l$ 's study $(32.1 \%)$ correlated well with the asymmetric group (32.6\%) in our study. Factors which may account for differences in the two studies include: different colour scales; different visual acuity entry criteria; and possible differences in the distribution of refractive errors.

Marked symmetry between two eyes of the same individual is a striking feature in normal corneas, as illustrated by analysis of multiple factors. Forty three per cent of right and left eyes were categorised into the same group based on pattern recognition and the high correlation of quantitative indices between the two eyes suggests a higher degree of mirror image symmetry as described by others. ${ }^{8}$ Mirror image symmetry also extended to the location of the apex for each cornea, as described by Edmund, ${ }^{17}$ and to the acute angle between the steepest radial axis above and below the horizontal meridian, a feature not previously reported. There was also a high degree of symmetry within an individual eye above and below the horizontal meridian, as seen from the results of both our pattern and quantitative analysis (I $-\mathrm{S}$ values).

The majority of corneas in our study sample were steepest centrally flattening towards the periphery, as previously reported. ${ }^{8} 91819$ Our findings that the central $K$ and $\operatorname{sim} K$ values are
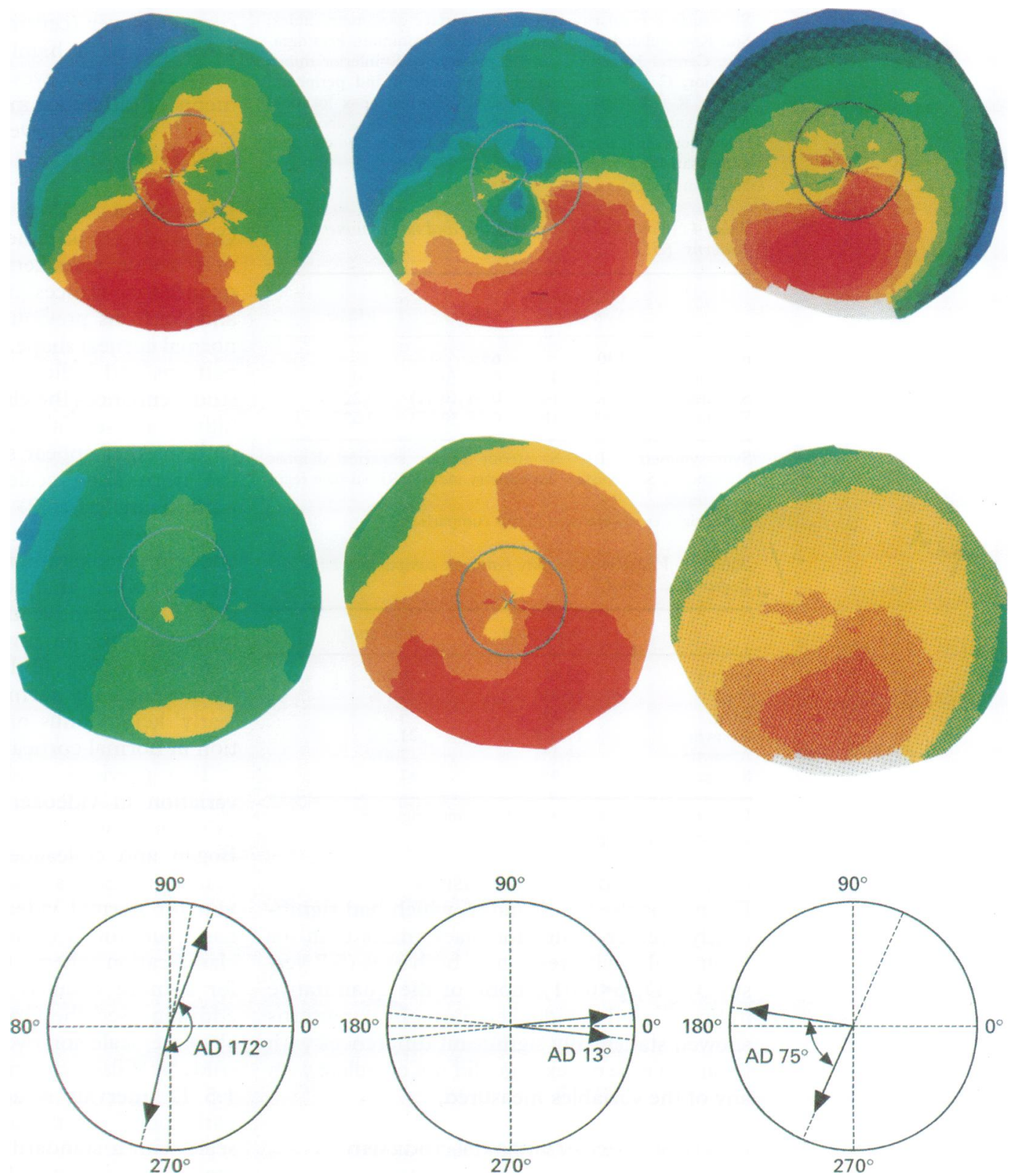

Figure 4 Videokeratographs (normalised scale) of three corneas, normal by slit-lamp examination (top row), accompanying pattern analysis (in absolute scale) (middle row), and quantitative indices illustrating differences among corneas (bottom row). (Note: solid arrows indicate steepest radial axis above and below the horizontal meridian.) (Left column) $A B / I S$ pattern ( $I-$ value $=1.53 \mathrm{D}$ (within 2-3 $D$ of normals), $A D=172$ degrees (only 8 degree shift from 180); (centre column) $A B / S R A X$ pattern $(I-S$ value $=1.21 D$ (within 2-3 SD of normals), $A D=13$ degrees (167 degree shift from 180); (right column) $A B / S R A X$ pattern (scissoring on retinoscopy with dilated pupil ('early' degree shift from 180$) ;$ (right column) $A B / S R A X$ pattern (scissoring on retinoscopy with dilated pupil
keratoconus) $(I-S$ value $=2.34 D$ ( $>3 S D$ of normals), $A D=75$ degrees (105 degree shift from 180$)$. 
of equal power suggests a region between 0.2 $\mathrm{mm}$ to $1.5 \mathrm{~mm}$ from the intersection of the line of sight and the cornea that may be part of the corneal cap, as described by Ericksen. ${ }^{20}$ We found the median site of the corneal apex (CA) to be superotemporal to the intersection of the line of sight and the cornea, located in any quadrant around this point and clustering in the vertical meridian. This is in agreement with the work of Edmund et al but contrasts with that of Bonnet et al and Tomlinson et al, who found no significant trend in the vertical meridian. ${ }^{21-23}$

The database of normal videokeratographs that we have compiled is not truly representative of the normal population in the strictest sense in that we excluded contact lens wearers, individuals with high degrees of ametropia and the very young and very old, necessary to capture high quality videokeratographs. Despite these limitations, defining the normal limits of videokeratography by pattern and quantitative index analysis as we have done in this study allows us to discern subtle deviations from normal corneal curvature that is not immediately obvious by looking at videokeratographs in the normalised scale. This is illustrated by comparing the pattern and index analysis of the three videokeratographs in Figure 4 (left and centre columns) (part of this data base) and Figure 4 (right hand column) (which does not form part of this data base). All three patients have normal slit-lamp evaluations and a cursory glance at videokeratographs analysed in the normalised scale would put all three into the $\mathrm{AB} / \mathrm{IS}$ category, with all three being considered as keratoconus 'suspects', as has been done in recent reports regarding keratoconus 'suspects' in the medical literature. ${ }^{24-26}$

Pattern analysis in the absolute scale using our classification scheme demonstrates that we can show differences between the three patterns. Figure 4 (left hand column) depicts an $\mathrm{AB} / \mathrm{IS}$ pattern ( $7.4 \%$ overlap with normals), and Figure 4 (centre and right hand columns) have $A B / S R A X$ patterns $(0.5 \%$ overlap with normals in this study). For individuals who have difficulty in recognising that these two patterns fall into different categories, the $\mathrm{AD}$ index is useful to differentiate the two: for Figure 4 (left), $\mathrm{AD}$ is 172 degrees (a mere 8 degree shift from 180) and for Figure 4 (centre), $\mathrm{AD}$ is 13 degrees (a 167 degree shift from 180) putting it into the AB/SRAX category. Using quantitative index analysis, further differences can be discerned between pattern 4 (centre) and 4 (right) both of which fall into the $A B / S R A X$ pattern category. Although the $\mathrm{AD}$ index shows a shift of greater than 30 degrees from 180 for both patterns (167 degrees for 4 (centre) and 95 degrees for 4 (right)), the I - S value for 4 (centre) is 1.2 $\mathrm{D}$ (within 2-3 SD of normals) and is $2.4 \mathrm{D}$ (>3 $\mathrm{SD}$ for normals) for 4 (right) suggesting an abnormal cornea. Subsequent retinoscopy with a dilated pupil of all three patients revealed 'scissoring of the red reflex' in 4 (right) only, confirming the presence of irregular astigmatism and a diagnosis of 'early' keratoconus. This patient depicted in Figure 4 (centre), an airforce recruit, was diagnosed as being clinically and topographically normal by several clinicians with extensive experience in managing keratoconus, immediately before being referred to our clinic.

Besides the utility of the database of normal videokeratographs and related quantitative indices compiled in this study to determine which videokeratography patterns should be considered as 'suspect' or keratoconus in screening for refractive surgery, other potential uses of this database are: its use as a baseline research tool for determining subtle deviations from normal corneal curvature in longitudinal topographic studies of family members of patients with familial keratoconus and a basis for developing a classification scheme for subclinical keratoconus based on videokeratography, as progression from normal topography to keratoconus is observed over time. We hope to demonstrate the utility of this database for these purposes in future reports of topographic studies currently in progress.

Supported in part by NIH grant EY09052, the Cedars-Sinai Young Investigators Research Award, and the Cedars-Sinai Young Investigators Research Award, and the

Presented in part at the ARVO Annual Meeting, Sarasota, May 1994, and the Cornea Federated Societies Meeting, Toronto, 23 June 1994.

1 Klyce SD. Computer-assisted corneal topography: highresolution graphic presentation and analysis of keratoscopy. Invest OphthalmolVis Sci 1984;25:1426-35.

2 Dingeldein SA, Klyce SD. Imaging of the cornea. Cornea 1988;7:170-82.

3 Wilson SE, Verity SM, Conger DL. Accuracy and precision of the corneal analysis system and the topographic modeling system. Cornea 1992;11:28-35.

4 Hannush SB, Crawford SL, Waring III GO, Gemmill MC. Reproducibility of normal corneal power measurements Reproducibility of normal corneal power measurements
with a keratometer, photokeratoscope, and video imaging with a keratometer, photokeratoscope, and
system. Arch Ophthalmol 1990;108:539-44.

5 Wilson SE, Klyce SD. Quantitative descriptors of corneal topography. A clinical study. Arch Ophthalmol 1991;109: 349-53.

6 Roberts C. The accuracy of 'power' maps to display curvature data in corneal topography systems. Invest Ophthalmol Vis Sci 1994;35:3525-32.

7 Klein SA, Mandell RB. Shape and refractive powers in corneal topography. Invest Ophthalmol Vis Sci 1995;36:2096109

8 Dingeldein SA, Klyce SD. The topography of normal corneas. Arch Ophthalmol 1989;107:512-8.

9 Bogan SJ, Waring III GO, Ibrahim O, Drews C, Curtis L. Classification of normal corneal topography based on computer-assisted videokeratography. Arch Ophthalmol 1990;108:945-9.

10 Gormley DJ, Gersten M, Koplin RS, Lubkin V. Corneal modeling. Cornea 1988;7:30-5

11 Rabinowitz YS, Garbus J, McDonnell PJ. Computerassisted corneal topography in family members of patients with keratoconus. Arch Ophthalmol 1990;108:365-71.

12 Rabinowitz YS, McDonnell PJ. Computer-assisted corneal topography in keratoconus. Refractive Corneal Surg 1989;5: 400-8.

13 Dixon WJ, ed. BMPD statistical software (Release 7). Los Angeles, CA: University of California Press, 1992.

14 Shapiro SS, Wilk MB. An analysis of test for normality (complete samples). Biometrika 1965;52:591-611.

15 Snedecor GW, Cochran WG. Statistical methods. Iowa: Iowa Snedecor GW, Cochran WG. Statistical
State University Press, 1980:175-85.

16 Wilson SE, Klyce SD, Husseini ZM. Standardized colorcoded maps for corneal topography. Ophthalmology 1900 13:1723-7.

17 Edmund C. Location of the corneal apex and its influence on the stability of the central corneal curvature: a photokeratoscopy study. Am $\mathcal{F}$ Optom Physiol Opt 1987;64:84652.

8 Bogan SJ, Maloney RK, Waring GO. Computer-assisted topographic analysis of corneal topography after radia keratotomy. Invest Ophthalmol Vis Sci 1990;31:30.

19 Clark BAJ. Mean topography of normal corneas. Aust $\mathfrak{f}$ Optom 1974;57:107-14

20 Aubert $\mathrm{H}$ or Ericksen, cited by Mandell RB. Contact len practice. 3rd ed. Springfield, II. Charles C Thomas, 1981. 1 Mandell RB, St Helen R. Position and curvature of the corneal apex. Am f Optom Physiol Opt 1969;46:25-9.

2 Bonnet R, Cochet P. New method of topographic ophthalmometry-its theoretical and clinical applications. Am f Optom Physiol Opt 1962;39:227-51. 
23 Tomlinson A, Schwartz C. The position of the corneal apex in the normal eye. Am f Optom Physiol Opt 1979;56:236-

24 Waring GO, Rabinowitz YS, Sugar J, Damiano R, Wilson $\mathrm{SE}$, Krachmer $\mathrm{J}$, et al. Nomenclature for keratoconus SE, Krachmer J, et al. Nomenclature for
suspects. Refract Corneal Surg 1993,9:219-21.
25 Grandon SC, Weber RA. Radial keratotomy in patients with atypical inferior steepening. F Cataract Refract Surg 1994;20:381-6.

26 Bowman CB, Thompson KB, Stulting RD. Refractive keratotomy in keratoconus 'suspects'. Refract Corneal Surg $1995 ; 11: 3,202-6$. 